\title{
PKM PEMBERDAYAAN KELOMPOK USAHA KERIPIK MANGROVE DESA TAMBAKREJO, SUMBERMANJING WETAN, KABUPATEN MALANG
}

\author{
Riril Mardiana Firdaus ${ }^{1}$, Roni Alim Ba'diya Kusufa ${ }^{2}$, Yoyok Seby Dwanoko ${ }^{3}$ \\ ${ }^{1}$ Fakultas Ekonomi dan Bisnis, Universitas Kanjuruhan Malang \\ ${ }^{2}$ Fakultas Ilmu Pendidikan, Universitas Kanjuruhan Malang \\ ${ }^{3}$ Fakultas Sain dan Teknologi, Universitas Kanjuruhan Malang \\ Email: 1ririlmardiana@unikama.ac.id; 2roniabk@unikama.ac.id; 3yoyokseby@unikama.ac.id
}

\begin{abstract}
Abstrak: Mangrove berfungsi sangat strategis dalam menciptakan ekosistem pantai yang layak untuk kehidupan organisme air dan darat. Mangrove memiliki fungsi fisik dan biologis, dan nilai ekonomi yang sangat tinggi. Fungsi fisik mangrove adalah untuk menahan abrasi pesisir, menjaga garis pantai dan limbah filter. Fungsi ekologi mangrove adalah sebagai ikan, kepiting dan bertelur terestrial. Sementara itu, mangrove ekonomi memiliki nilai ekonomi yang sangat tinggi. Jenis mangrove jeruju, daunnya dapat digunakan sebagai bahan baku untuk keripik. Tujuan dari pengabdian ini adalah untuk memberdayakan masyarakat dusun Sendangbiru dalam meningkatkan: (1) produksi keripik mangrove (2) Kemasan dengan desain berlabel stiker (3) memperluas pemasaran dan (4) pengelolaan keuangan hasil bisnis. Pengabdian ini berlangsung di rumah mitra, Jl. Lintas Kalipal RT 30, desa Tambakrejo, Kecamatan Sumbermanjing Wetan, Kabupaten Malang. Metode yang ditawarkan dalam program kemitraan masyarakat (PKM) ini adalah: (1) sosialisasi, pelatihan, dan bantuan dalam meningkatkan produksi keripik mangrove dengan peralatan produksi yang sesuai. (2) pelatihan dan bantuan dalam pembuatan kemasan chip mangrove dengan stiker label dan desain segel elektrik sehingga Kemasan lebih menarik dan tidak rentan terhadap kebocoran (3) Bantuan pelatihan dan pemasaran melalui media online, (4) pelatihan dan manajemen keuangan untuk hasil bisnis. Sebagai hasil dari program kemitraan masyarakat, mitra dapat: (1) meningkatkan jumlah produksi chip mangrove dengan baik, (2) membuat kemasan chip mangrove dengan desain label stiker dan kemasan menggunakan siller listrik, (3) Perluasan jaringan pemasaran melalui media online, dan mengelola hasil keuangan operasi dengan baik.
\end{abstract}

Kata kunci: PKM, pemberdayaan, kelompok usaha keripik mangrove, Kelurahan Tambakrejo Sumbermanjing Wetan Kabupaten Malang

\begin{abstract}
Mangroves function very strategically in creating viable coastal ecosystems for the life of aquatic and terrestrial organisms. Mangroves have physical and biological functions, and very high economic value. The physical function of mangroves is to resist coastal abrasion, maintain coastlines and filter waste. The ecological function of mangroves is as a fish, crab and terrestrial spawning. Meanwhile, economically mangroves have very high economic value. Jeruju mangrove type, its leaves can be used as raw material for chips. he purpose of this service is to empower, Sendangbiru hamlet community in improving: (1) Production of mangrove chips (2) Packaging with sticker labeled design (3) Expanding marketing and (4) Financial management of business results. This service takes place at a partner's house, Jl. Lintas Kalipal RT 30, Tambakrejo Village, Sumbermanjing Wetan District, Malang Regency. The methods offered in the community partnership program (PKM) are: (1) Socialization, training, and assistance in increasing the production of mangrove chips with appropriate production equipment. (2) Training and assistance in making mangrove chip packaging with label stickers and electric seal design so that the packaging is more attractive and not prone to leakage (3) Training and marketing assistance through online media, (4) Training and financial management assistance for business results.As a result of the community partnership program, partners are able to: (1) Increase the amount of mangrove chip production well, (2) Make mangrove chip packaging with sticker label design and packaging using electric siller, (3) Expand marketing networks through online media, and Manage financial results of operations well.
\end{abstract}

Keywords: PKM, Empowerment, Mangrove chips business group, Tambakrejo Village Sumbermanjing Wetan Sub District Malang Regency. 


\section{PENDAHULUAN}

Mangrove berfungsi sangat strategis dalam menciptakan ekosistem pantai yang layak untuk kehidupan organisme perairan dan daratan. Ekosistem mangrove dapat tumbuh dan berkembang dengan baik dalam kondisi dimana terjadi penggenangan dan sirkulasi air permukaan yang menyebabkan pertukaran dan pergantian sedimen secara terus menerus (Dahuri, dkk. 2013). Mangrove mempunyai fungsi fisik dan biologis, serta nilai ekonomis yang sangat tinggi. Fungsi fisik mangrove adalah menahan abrasi pantai, menjaga garis pantai dan penyaring sampah. Fungsi ekologis mangrove adalah, sebagai pemijahan ikan, kepiting dan satwa darat. Sementara itu, secara ekonomis mangrove mempunyai nilai ekonomi yang sangat tinggi. Tidak banyak diketahui oleh masyarakat umum, bahwa daun mangrove jenis jeruju dapat dijadikan bahan olahan keripik mangrove.

Mangrove jenis jeruju merupakan tanaman vegetasi mangrove yang tumbuh secara alami di daerah pesisir. Selain terkenal sebagai tanaman obat-obatan, jeruju juga dapat dimanfaatkan sebagai bahan pangan (Herwanti dan Febryano, 2017). Jeruju dapat difungsikan dalam pemulihan kualitas perairan yang tercemar. Jeruju mampu menyerap logam berat $\mathrm{Pb}$ dan $\mathrm{Cd}$ yang merupakan unsur pencemar, (Irawanto, 2015). Selain memiliki kemampuan dalam menyerap atau menyaring kotoran limbah, jeruju memiliki banyak manfaat lainnya sebagai obat-obatan tradisional (Ganesh dan Vennila, 2011; Sarno, 2013; Saptiani, 2013) .

Tabel 1. Profil Mitra

\begin{tabular}{|c|c|c|}
\hline No & Uraian Profil & Data \\
\hline$\overline{1}$ & Nama Kelompok & Usaha Keripik Mangrove Jeruju \\
\hline 2 & Alamat & $\begin{array}{l}\text { Jl. Lintas Kalipal RT 30, Dusun } \\
\text { Sendangbiru Desa Tambakrejo } \\
\text { Kecamatan Sumbermanjing } \\
\text { Wetan Kabupatn Malang }\end{array}$ \\
\hline 3 & Nama Ketua & $\begin{array}{l}\text { Ibu Sutrani } \\
\text { sutrani@yahoo.com }\end{array}$ \\
\hline 4 & $\begin{array}{l}\text { Jumlah Anggota/ } \\
\text { Karyawan }\end{array}$ & 5 orang \\
\hline 5 & Jumlah Produksi & $\begin{array}{l}\text { Mitra hanya mampu } \\
\text { memproduksi } 15 \mathrm{~kg} \text { keripik } \\
\text { Mangrove }\end{array}$ \\
\hline 6 & $\begin{array}{l}\text { Rerata Omzet per } \\
\text { Bulan }\end{array}$ & $\begin{array}{l}\text { Dalam } 1 \text { bulan mitra mampu } \\
\text { memproduksi } 15 \mathrm{~kg} \times 30 \text { hari = } \\
450 \mathrm{~kg} . \times 18.000= \\
\text { Rp. } 8.100 .000,- \\
\text { Jadi dalam } 1 \text { bulan omzetnya } \\
\text { sekitar } \\
\text { Rp. } 8.100 .000,-\end{array}$ \\
\hline 7 & $\begin{array}{l}\text { Rerata Pendapatan } \\
\text { per Bulan }\end{array}$ & $\begin{array}{l}\text { Rerata pendapatan mitra per } \\
\text { bulannya sekitar Rp. } 4.050 .000 \text {,- }\end{array}$ \\
\hline
\end{tabular}

Tidak banyak diketahui oleh masyarakat Dusun Sendangbiru, Desa Tambakrejo, yang bertempat tinggal di sekitar pantai Clungup Sendangbiru Kabupaten Malang, bahwa daun mangrove Jeruju dapat dijadikan bahan olahan keripik.
Namun Ibu Sutrani telah memanfaatkan daun mangrove Jeruju sebagai bahan olahan keripik. Tetapi produksi dan proses pengemasannya masih sederhana, begitu juga pemasaran dan pengelolaan keuangan hasil usaha masih belum maksimal.

Mitra menggunakan peralatan seadanya dalam memproduksi keripik mangrove jeruju

Tabel 2. Permasalahan Mitra

\section{No Permasalahan Mitra}

1. Produksi:

- Produksi masih menggunakan peralatan seadanya,

- Hasil produksi terbatas dan belum mampu memenuhi permintaan pasar

2. Kemasan

- Pengemasan keripik mangrove masih menggunakan sulut api sehingga kemasan rawan bocor dan keripik mangrove mudah lembek

- Kemasan belum ada lebel stiker, dan

- Belum ada P-IRT

3. Pemasaran:

- Pemasaran masih dititipkan di warung-warung kecil di desanya

- Belum pernah dipasarkan melalui website atau online

4. Manajemen Keuangan:

- Manajemen keuangan hasil usahan masih belum terencana dengan baik

- Harapan kedepannya semua laporan keuangan berbasis komputerisasi.

Tabel 3. Permasalahan Mitra yang Diselesaikan

No Permasalahan Mitra Yang Diselesaikan

1. Produksi:

- Merubah alat konvensional dengan Merancang mesin produksi keripik Mangrove Jeruju yang lebih paktis, produktif dan efektif.

- Pelatihan dan pendampingan produksi keripik mangrove dengan alat yang lebih paktis, produktif dan efektif.

2. Kemasan:

- Pengemasan keripik mangrove menggunakan alat siller listri agar kemasan lebih praktis dan tidak bocor, sehingga keripik tidak mudah lembek.

- Kemasan diberi label stiker bontaq yang didesain sesuai konten produk yang ditawarkan, sehingga produk lebih menarik dan diminati oleh konsumen - Pengajuan P-IRT.

3. Pemasaran:

- Pelatihan dan pendampingan pemasaran melalui website atau online

- Keripik Mangrove Jeruju ini dikemas dan dipasarkan dengan harga:.

1. Netto; 50gr, = Rp. 4.000,-

2. Netto; $100 \mathrm{gr},=8.000$, - dan

3. Netto; 150gr. Rp. 12.000,-

4. Manajemen Keuangan:

- Pelatihan dan pendampingan serta monitoring manajemen keuangan hasil usahan agar terencana dengan baik

Tujuan program kemitraan masyarakat (PKM) ini, membantu mitra dalam menyelesaiakn permasalahan yang dihadapi. Dari analisis situasi dan diskusi dengan mitra, maka tim PKM dan Mitra 
sepakat menyelesaian permsalahan yang disajikan pada tabel 3 .

\section{METODE PELAKSANAAN}

Berdasarkan tabel 3 diatas maka metode yang ditawarkan dalam program kemitraan masyarakat (PKM) ini adalah: (1) Sosialisasi, pelatihan, dan pendampingan serta monitoring pembuatan keripik mangrove jeruju dengan alat produksi yang layak. (2) Pelatihan, dan pendampingan membuat kemasan keripik mangrove jeruju dengan desain label stiker serta menggunakan siler listrik agar kemasan lebih menarik dan tidak mudah bocor dan pengajuan P-IRT (3) Pelatihan dan pendampingan memperluas pemasaran melalui media online, (4) Pelatihan dan pendampingan manajemen keuangan dengan baik.

\section{HASIL DAN PEMBAHASAN}

Program Kemitraan Masyarakat (PKM) Universitas Kanjuruhan Malang diselenggarakan pada Juni - Oktober 2019. Tim tersebut terdiri dari: (1) Riril Mardiana Firdaus, S.Pd., M.M. sebagai ketua, (2) Roni Alim Ba'diya Kusufa, M.Pd. sebagai anggota 1 dan Yoyok Seby Duanoko sebagai anggota 2. Tim PKM tersebut memiliki kualifikasi keahlian di bidangnya masing-masing yang mana dapat membantu permasalahan mitra.

Program kemitraan masyarakat (PKM) di Desa Tambakrejo, Sumbermanjing Wetan, Kabupaten Malang dilaksanakan dalam beberapa tahap sebagai berikut:

Pertama: Sosialisasi program kemitraan masyarakat (PKM) dihadiri oleh mitra dan berlangsung di rumah mitra Jl. Lintas Kalipal RT 30, Dusun Sendangbiru Desa Tambakrejo Kecamatan Sumbermanjing Wetan Kabupatn Malang.

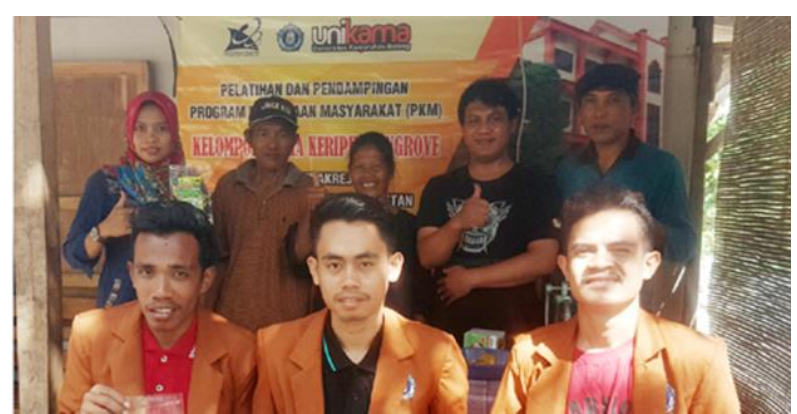

Gambar 1. Sosialisasi Program kemitraan masyarakat (PKM)

Sosialisasi program kemitraan masyarakat (PKM) membahas tentang persiapan produksi, pengemasan, dan pemasaran online serta manajemen keuangan hasil usaha. Pada tahap perencanaan ini bertujuan untuk mempersiapkan mitra agar mampu dan bersedia menyediakan tempat dan bahan-bahan yang diperlukan pada saat pelaksanaan program PKM. Hasil sosialisasi menunjukkan bahwa mitra sangat antuasias dalam mengikuti sosialisasi PKM dari tim pengabdi Universitas Kanjuruhan Malang.

Kedua: Pelaksanaan program kemitraan masyarakat (PKM) yang diawali dengan mempersiapkan bahan-bahanti seperti, daun mangrove jeruju, tepung tapeoka, garam, telor dan minyak goreng serta peralatan yang digunakan seperi, gunting, timbangan, wajan, sotil, serok, kompor gas dan alat pengemasan siller listrik. Langkah selanjutnya melakukan pelatihan dan pendampingan produksi keripik mangrove yang lebih gurih enak dan lezat dengan pilihan rasa Original, Balado, keju dan Barbaque. Beberapa varian rasa di ciptakan untuk memperbanyak produksi mangrove dan menarik minat konsumen konsumen untuk membeli.

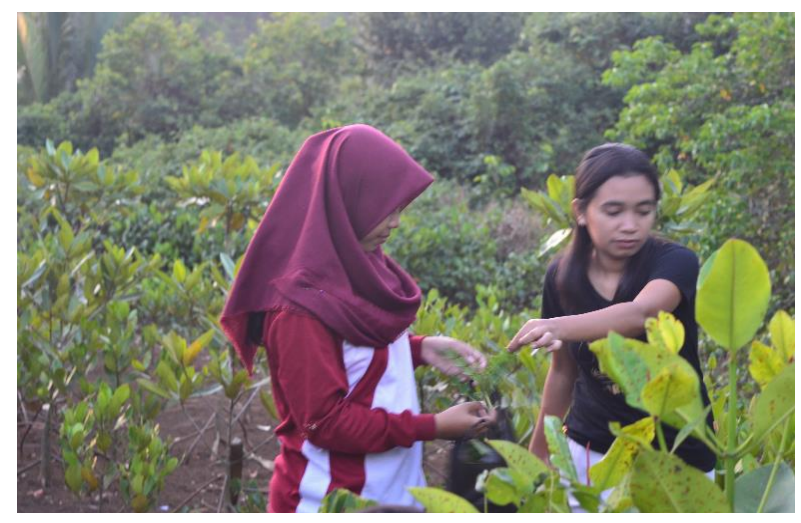

Gambar 2. Pengambilan bahan baku mangrove jeruju disekitar pantai Clungup, Sendangbiru, Malang

Setelah proses pengambilan bahan baku, langkah selanjutnya daun mangrove jeruju dipilih yang muda dan dihilangkan duru-durinya dengan gunting. Langkah selanjutnya menyiapkan bahanbahan seperti: tepung beras, tepung kanji, rempahrempah, telor dan garam serta air secukupnya. Bahan tersebut dibuat adonan sesuai dengan keinginan dan daun mangrove dimasukkan kedalam adonan.

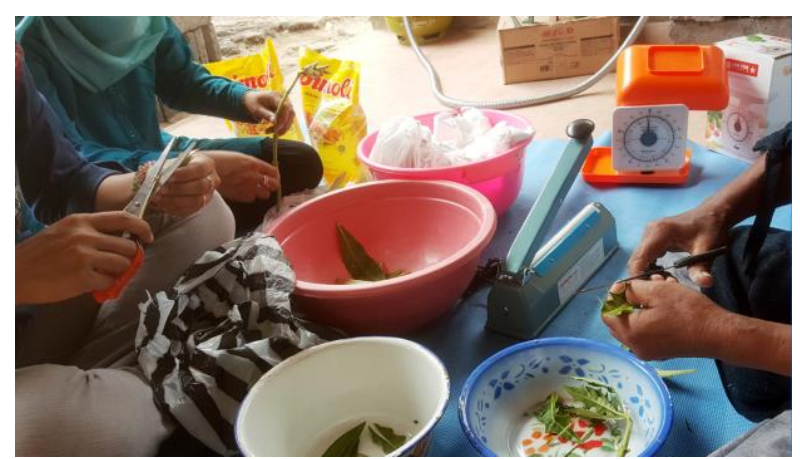

Gambar 3. Daun mangrove jeruju dan peralatan yang digunakan 


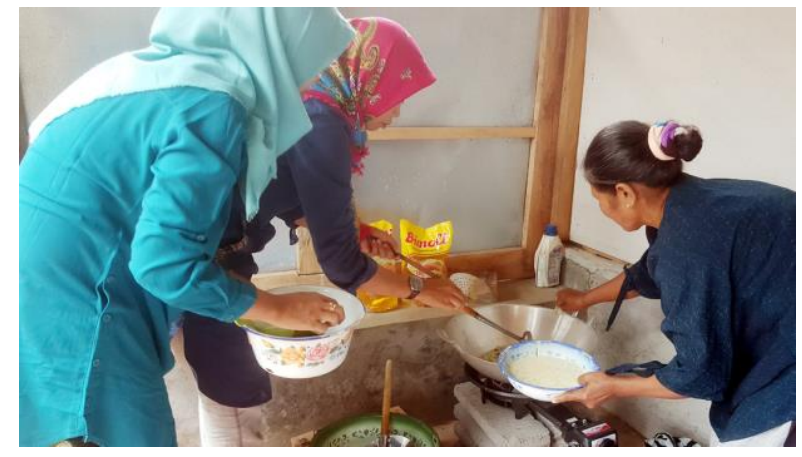

Gambar 4. Proses penggorengan daun mangrove yang sudah dicampur dengan bahan-bahan adonan

Selanjutnya menentukan desain kemasan yang lebih menarik dan unik, sehingga menarik minat konsumen utuk membeli keripik tersebut. Bahan label terbuat dari stiker bontak yang didesain dengan warna hijau ada dasar gambar daun mangrove jeruju dan mangrove yang sudah digoreng. Tidak lupa ada tuisan komposisi, logo halal, dan masa kadaluarsa.

Kemasan adalah hal yang penting dalam pembuatan produk, jika kemasan menarik maka juga akan menarik minat pembeli.

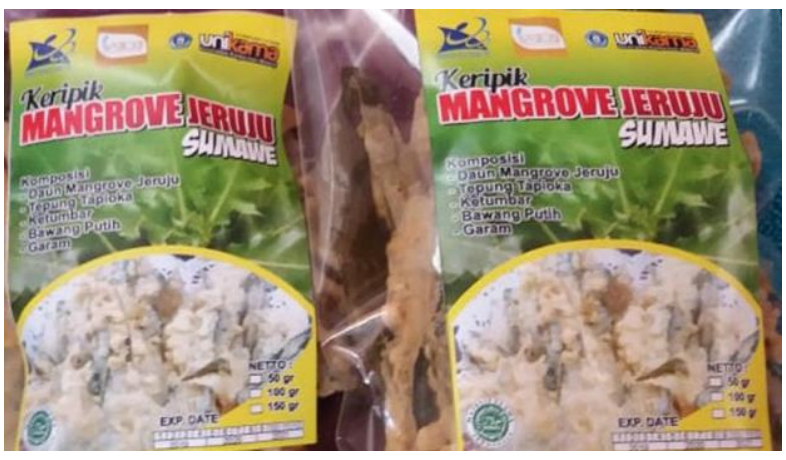

Gambar 5. Tampilan desan label produk berbahan stiker bontak.

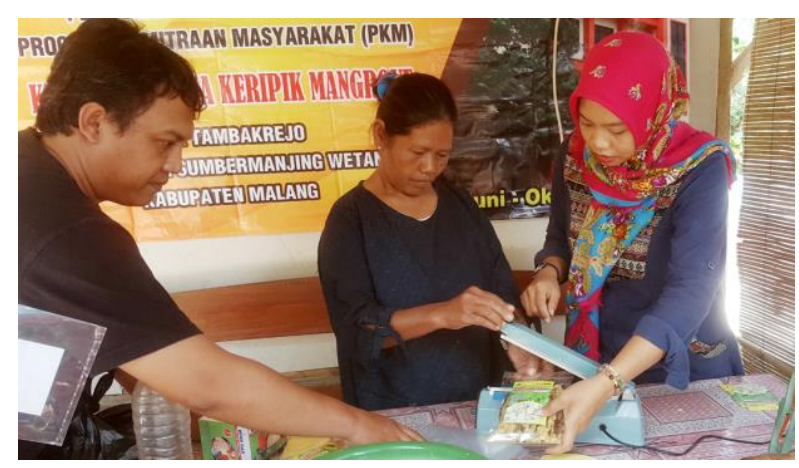

Gambar 6. Proses pengemasan keripik mangrove menggunakan alat siller listrik

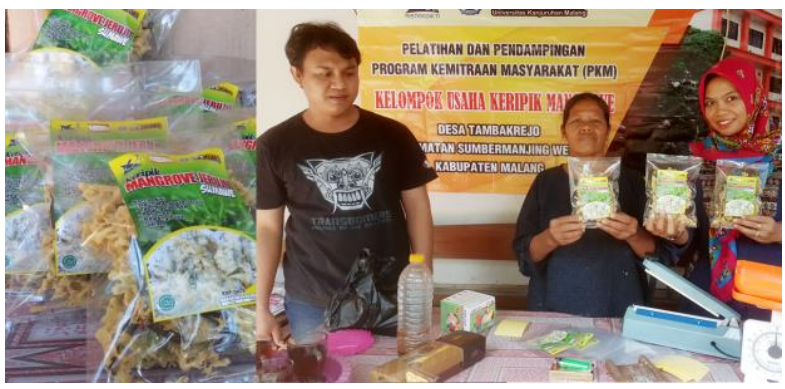

Gambar 7. Keripik Mangrove dengan kemasan baru, berlabel stiker siap dipasarkan.

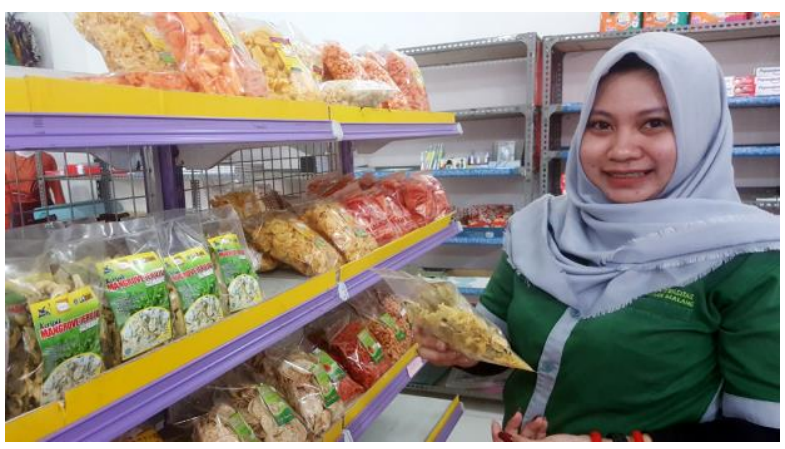

Gambar 8. Pemasaran Keripik Mangrove di Mini Market Kopma Universitas Kanjuruhan Malang

Tabel 4. Analisis Hasil Usaha Penjualan Keripik Mangrove Sebelum dan Sesudah PKM

\begin{tabular}{|c|c|c|c|c|}
\hline No. & Keterangan & Sebelum PKM & Sesudah PKM & Peningkatan \\
\hline$\underline{1}$ & Nama Mitra & Sutrani & & \\
\hline$\overline{2}$ & Alamat Mitra & $\begin{array}{l}\text { Jl. Lintas Kalipal RT 30, Dusun } \\
\text { Sendangbiru Desa Tambakrejo } \\
\text { Kecamatan Sumbermanjing Wetan } \\
\text { Kabupatn Malang }\end{array}$ & $\begin{array}{l}\text { Jl. Lintas Kalipal RT 30, Dusun } \\
\text { Sendangbiru Desa Tambakrejo } \\
\text { Kecamatan Sumbermanjing } \\
\text { Wetan Kabupatn Malang }\end{array}$ & - \\
\hline 3 & Jumlah Karyawan & 5 & 5 & - \\
\hline$\overline{4}$ & $\begin{array}{l}\text { Jumlah Produksi } \\
\text { per-Hari }\end{array}$ & $15 \mathrm{~kg}$ & $25 \mathrm{~kg}$ & $15 \mathrm{~kg}$ \\
\hline 5 & Kemasan & $\begin{array}{l}\text { Belum ada label stiker dan masih } \\
\text { menggunakan sulut apai }\end{array}$ & $\begin{array}{l}\text { Menggunakan label stiker dan } \\
\text { pengemasan menguunakan siller } \\
\text { listrik }\end{array}$ & $\begin{array}{l}\text { Peningkatan kualitas } \\
\text { desain kemasan produk }\end{array}$ \\
\hline 6 & Varian Rasa & Rasa original & 4 Varian Rasa & $\begin{array}{l}\text { Peningkatan varian } \\
\text { rasa }\end{array}$ \\
\hline 7 & Pemasaran & $\begin{array}{l}\text { Dititipkan di warung-warung kecil } \\
\text { sekitar rumah }\end{array}$ & $\begin{array}{l}\text { Di pasarkan melalui Mini market } \\
\text { dan media online }\end{array}$ & Pemasaran lebih luas \\
\hline 8 & $\begin{array}{l}\text { Rerata Omzet per } \\
\text { Bulan }\end{array}$ & Rp. 8.100.000,- & Rp. 12.000 .000 & Omset Meningkat \\
\hline 9 & $\begin{array}{l}\text { Rerata Pendapatan } \\
\text { per Bulan }\end{array}$ & Rp. 4.050.000,- & Rp. 6.000 .000 & Pendapatan Men \\
\hline
\end{tabular}




\section{KESIMPULAN}

Program Kemitraan Masyarakat (PKM) Universitas Kanjuruhan Malang diselenggarakan pada Juni - Oktober 2019. Tim tersebut terdiri dari: (1) Riril Mardiana Firdaus, S.Pd., M.M. sebagai ketua, (2) Roni Alim Ba'diya Kusufa, M.Pd. sebagai anggota I dan Yoyok Seby Duanoko sebagai anggota II. Program kemitraan masyarakat (PKM) dilaksanakan dalam beberapa tahap sebagai berikut:

1. Sosialisasi program kemitraan masyarakat (PKM) dihadiri oleh mitra dan berlangsung di rumah mitra. Hasil sosialisasi menunjukkan bahwa mitra sangat antuasias dalam mengikuti kegiatan PKM dari tim pengabdi Universitas Kanjuruhan Malang.

2. Pelaksanaan program kemitraan masyarakat (PKM) diawali dengan mempersiapkan bahanbahan dan peralatan yang dibutuhkan. Langkah selanjutnya melakukan pelatihan dan pendampingan produksi keripik mangrove yang lebih gurih enak dan lezat dengan beberapa varian rasa.

3. Desain kemasan dibuat sedemikian rupa agar lebih menarik, label kemasan berbahan stikernontaq, dan didlam label di cantumkan bahan dan komposisi produk. Selanjutnya, kemasan di pres dengan sealer listrik, sehingga kemasan tidak mudah bocor dan keripik tidak mudah lembek.

4. Pemasaran keripik mangrove jeruju, dipasarkan melalui mini market dan online, tujuannya agar produk dikenal masyarakat luas.

5. Pengelolaan keuangan hasil usaha sudah direncanakan, mulai dari perencanaan jangka pendek, menengan dan panjang. Dengan adanya perencanaan mitra dapat memngelola keuangannya dengan baik dan benar.

Ucapan terimakasih disampaikan kepada:

1. DRPM kemenristek dikti yang telah mendanai program kemitraan masyarakat (PKM) ini.
2. LPPM universitas kanjuruhan malang yang telah memberikan fasilitas dan mengakomudasi terlaksananya program kemitraan masyarakat (PKM) ini

3. Mita kelompok usaha keripik mangrove desa Tambakrejo, Kabupaten Malang yang telah mensukseskan program kemitraan masyarakat (PKM) ini dan semua pihak yang tidak bisa disebutkan satu-persatu.

\section{DAFTAR PUSTAKA}

Dahuri, R. 2013. Pengelolaan Sumberdaya Wilayah Pesisir Dan Lautan Secara Terpadu. Balai Pustaka. Jakarta.

Herwanti. Febryano. 2017. Analisis Finansial Produk Olahan Jeruju (Acanthus Micifolius) Di Desa Margasari Kecamatan Labuhan Maringgai Lampung Timur.(onlie) http://repository. lppm.unila.ac.id/4181/1/Herwanti\%20dan\%20F ebryano\%202017.pdf

Irawanto R, Ariyanti EE, Hendrian R. 2015. Jeruju (Acanthus ilicifolius): Biji, perkecambahan dan potensinya Seaholly (Acanthus ilicifolius): Seed, germination and uses. Pros Sem Nas Masy Biodiv Indon 1(5): 1011-1018. Bandung.

Ganesh S, Vennila JJ. 2011. Phitochemical analysis of Acanthus ilicifolius and Avicennia officinalis by GC - MS. Research Journal of Phitochemsitry 5(1):60 - 65.

Sarno, Marisa H, Sa'Diah S. 2013. Beberapa jenis mangrove tumbuhan obat tradisional di Taman Nasional Sembilang, Banyuasin, Sumatera Selatan. Jurnal Penelitian Sains 16 (3): 92-98.

Saptiani G, Prayitno SB, Anggoro S. 2013. Potensi anti bakteri ekstrak daun jeruju (Acanthus ilicifolius) terhadap Vibrio harveyi secara in vitro. Jurnal Kedokteran Hewan 7 (1): 17-20. 